\title{
A estilística de Machado de Assis em Oliver Twist e "Miss Dollar"
}

\section{The stylistics of Machado de Assis in Oliver Twist and "Miss Dollar"}

Danielle Franco Brunismann*

Mirian Ruffini**

Resumo: Este artigo tem por objetivo analisar duas publicações da primeira tradução de Oliver Twist para o português brasileiro, traduzida pelos escritores brasileiros Machado de Assis e Ricardo Lísias. Pretende-se identificar a estilística de Machado de Assis enquanto tradutor, por meio do romance, e escritor, pelo conto “Miss Dollar".

Palavras-chave: Tradução; Estilística; Machado de Assis; Oliver Twist; “Miss Dollar”.

Abstract: This paper aims to analyze two publications of the first translation of Oliver Twist to Brazilian Portuguese, translated by Brazilians writers Machado de Assis and Ricardo Lísias. In this paper, it is intended to identify the stylistics of Machado de Assis the translator, by means of the novel, and the writer, through the tale "Miss Dollar".

Keywords: Translation; Stylistics; Machado de Assis; Oliver Twist; “Miss Dollar”.

* Mestra em Letras, pelo Programa de Pós-Graduação em Letras - PPGL, da Universidade Tecnológica Federal do Paraná (UTFPR) Campus Pato Branco. Licenciada em Letras Português/Inglês pela UTFPR Campus Pato Branco. E-mail: daniellebrunismann@alunos.utfpr.edu.br

** Docente do Programa de Pós-graduação em Letras da Universidade Tecnológica Federal do Paraná (UTFPR), Campus Pato Branco. Doutora em Estudos da Tradução pela Universidade Federal de Santa Catarina. E-mail: mirianr@utfpr.edu.br 


\section{Machado de Assis em Oliver Twist e "Miss Dollar"}

Neste artigo pretende-se analisar as marcas tradutórias da primeira tradução de Oliver Twist (1838), de Charles Dickens, para o português brasileiro, realizada por Machado de Assis. Esse livro dickensiano foi inserido no sistema literário brasileiro no ano de 1870 , por meio de folhetim no Jornal da Tarde.

A principal peculiaridade dessa tradução brasileira consiste no fato de que seu primeiro tradutor, o escritor brasileiro Machado de Assis, traduziu apenas uma parte do romance, precisando interromper a atividade no capítulo 28. Após mais de um século dessa primeira tradução, a editora Hedra a selecionou para compor a sua coleção denominada 'Tradutores'. Ao optar por publicar o romance completo, e não apenas os capítulos traduzidos por Machado de Assis, os editores convidaram o escritor Ricardo Lísias para finalizar a tradução.

Desse modo, essa pesquisa molda-se sob a perspectiva dos Estudos da Tradução, e seu objetivo geral consiste em identificar traços da escrita machadiana na tradução de Oliver Twist, para posteriormente desenvolver uma análise de corpus paralelo entre o romance de Dickens e o conto "Miss Dollar", escrito por Machado de Assis e publicado em 1870, observando as possíveis semelhanças estilísticas em ambas as obras.

A escolha pelo conto "Miss Dollar" deu-se pelos pontos de contato com o romance dickensiano Oliver Twist. Ambas as obras foram publicadas no Brasil em 1870, sob a perspectiva do mesmo período histórico. Além disso, o escritor do conto também é o tradutor do romance, o que nos permite verificar se há semelhanças estilísticas nos textos em português. Vale ressaltar a particularidade dessa tradução, tanto pelo aspecto histórico quanto pela genialidade de Machado de Assis, que advêm de sua atuação como autor, e poderá ser observada neste artigo por meio do conto.

No conto, Machado de Assis, utiliza estrangeirismos ao integrar termos em inglês e francês. Vale destacar que Machado de Assis traduziu Oliver Twist a partir de uma edição francesa, pois não tinha muita familiaridade com o inglês. A 
respeito desse aspecto, em “Miss Dollar" o autor apropria-se mais dos estrangeirismos franceses. Por fim, as duas obras estão relacionadas aos três idiomas, português, francês e inglês.

Nesta pesquisa, utiliza-se como aporte teórico a Teoria dos Polissistemas, elaborada por Itamar Even-Zohar (1990), a qual apresenta a estruturação do polissistema cultural e dos sistemas que o compõem, proporcionando a compreensão e análise das relações entre os elementos culturais, sociais e literários.

No caso do estudo de literatura traduzida, envolvem-se dois polissistemas: o contexto de partida (ou de produção) e a cultura de chegada (ou de recepção). Neste estudo, estabelece-se por polissistema de partida a Inglaterra Vitoriana, período que abrange o reinado da rainha Vitória (1837-1901). Além disso, outros elementos culturais e sociais desse período, como a Revolução Industrial e a promulgação da Lei dos Pobres de 1834, que regia as workhouses (abrigos de mendicidade), influenciaram a produção de Oliver Twist, pois esses acontecimentos e as suas consequências foram utilizados por Dickens para estruturar o romance. O polissistema de chegada da obra é o sistema literário brasileiro oitocentista, período em que a cultura brasileira foi influenciada pela cultura francesa em alguns sistemas da sociedade, como na literatura.

No conto "Miss Dollar", Machado traz citações em francês, o que demonstra o seu conhecimento e interesse pela língua e cultura francesa: “Miss Dollar tem uma coleira ao pescoço fechada por um cadeado em que se leem as seguintes palavras: De tout mon coeur ${ }^{1}$." (Assıs 1994: p. 3). Há também referências a escritores e obras francesas.

A partir dos pressupostos de Even-Zohar, pode-se considerar que o sistema literário brasileiro passava por um processo de transição e amadurecimento, pois, ao traduzir obras para o português brasileiro, buscou-se a literatura estrangeira como instrumento de manutenção do sistema literário. Segundo Candido (2002):

1 De todo o meu coração. (tradução nossa).

TradTerm, São Paulo, v.35, junho/2020, p. 164-185 www.revistas.usp.br/tradterm 
A vida cultural se desenvolveu muito nos decênios de 1860 e 1870, caracterizando-se este último pelo grande progresso material, [...]. Foram então fundadas ou reorganizadas escolas de ensino superior, o jornalismo ganhou tonalidade mais moderna e houve notável progresso na produção de livros, graças a algumas casas editoras das quais ressalta a Garnier, que promoveu a publicação em escala apreciável de autores brasileiros do passado e do presente, sem falar no incremento de obras traduzidas. [...] Na poesia e no romance continuam nessa fase as linhas já indicadas, mas surgem alguns traços que acentuam as suas características e anunciam desenvolvimentos novos. (69-70).

Como citado por Candido (2002), as mudanças ocorreram em diversos sistemas do Brasil do século XIX. Especificamente no sistema literário, desenvolveu-se a produção de livros e introduziram-se traduções de obras da literatura mundial. Nesse sentido, em Machado de Assis: tradutor, Massa (2008) analisa obras traduzidas por Machado de Assis. No capítulo "As vozes do tradutor”, o autor aponta indícios de que a tradução de Oliver Twist tenha sido feita a partir de uma encomenda ou de uma demanda:

Há uma encomenda ou uma demanda quando uma obra alimenta o consumo do público, na qual a orientação ou a utilização não depende essencialmente do tradutor. As peças teatrais e os romances estão nesse caso, mesmo se intervenção de Machado de Assis possa chegar à escolha de um título. Esses textos são geralmente apresentados em sua totalidade. Eles entram em consumo porque a produção nacional é insuficiente: os romances - os franceses sobretudo - alimentam os rodapés dos cotidianos e, apesar dos esforços dos dramaturgos brasileiros, o repertório nacional não consegue alimentar a cena devoradora do Rio ou às vezes os espetáculos ficam em cartaz por umas poucas noites. (57).

O aporte teórico deste estudo também é composto por Tradução reescrita e manipulação da fama literária (2007) de André Lefevere, para a identificação da atuação do mecenato durante o processo de tradução do romance; e Escândalos da Tradução (2002) de Lawrence Venuti, em que o autor discorre acerca dos conceitos de domesticação, estrangeirização e resíduo, que são as marcas tradutórias impressas no texto traduzido. Essas marcas podem ser 
inseridas intencionalmente a partir da supressão de termos estrangeiros, ou da substituição por termos da cultura-alvo, que podem ser nomes de cidades, ruas, locais, entre outros. No caso de Oliver Twist, o tradutor utiliza o recurso de domesticação de nomes estrangeiros, como veremos mais detalhadamente no desenvolvimento desse estudo.

\section{Os autores e as obras}

Considerado o autor mais popular da Era Vitoriana, Charles John Huffam Dickens foi um escritor britânico que no decorrer dos seus 35 anos de produção, transitou entre diversos estilos literários. 0 autor nasceu em Landport, em 07 de fevereiro de 1812, e viveu uma infância conturbada, repleta de experiências negativas, como a prisão de seu pai, o trabalho nas fábricas, a pobreza que sua família viveu e a desigualdade social.

A produção literária realista de Dickens apresenta lugares e realidades que, por vezes, são desconhecidos dos leitores, pois descreve os becos e vielas repletos de pobreza e violência, revelando as mais diversas faces da miséria humana, como o abandono, a vingança e a avareza. É importante ressaltar que essa parte da literatura dickensiana é considerada pioneira em ter por cenário o centro urbano, além de adotar a figura da criança como protagonista em alguns romances.

Foi considerado um dos maiores autores britânicos reconhecidos ainda em vida, "Tudo porque Dickens, embora dissentindo dos erros do seu tempo, possuía a mesma sensibilidade da gente de sua época. Ajudava-o muito nisso o que nele havia de profundamente popular" (MENDES 1983: 70). O autor tematizou em suas narrativas acontecimentos da sociedade inglesa do século XIX, como a Revolução Industrial e suas consequências ao proletariado.

Além disso, a articulação da denúncia e crítica com humor é uma das características mais predominantes na escrita de Dickens. Puglia afirma que essa 
junção de estratégias em Oliver Twist demonstra que:

[...] uma crítica mais severa começa a ser feita, principalmente quando a gangue dos ladrões mirins serve como imitação, em tom de chacota, das maquinações e das idéias [sic] firmemente aceitas pelas elites: pelo humor, a canalhice da grande burguesia é caricaturizada pelo modus operandi da quadrilha dos garotos mas as conexões não são imediatas, prevalecendo uma ordem confiante no pacífico convívio entre classes. (2006: 159-160).

Nesse sentido, compreende-se que nesse romance Dickens expõe, sutilmente, a sua desaprovação aos hábitos desenvolvidos pelas classes sociais, e o faz sem provocar desarmonia na sociedade.

Oliver Twist foi publicado originalmente em folhetim na revista literária Bentley's Miscellany, no período de fevereiro de 1837 a abril de 1839. Tem-se o registro de que a primeira edição completa do romance de Dickens foi publicada em 1838. Nessa obra, o narrador discorre sobre a vida de um menino órfão e pobre que sofre com a realidade do Período Vitoriano.

No ano de 1870 foi publicada a obra Contos Fluminenses, livro que reúne um conjunto de contos de Machado de Assis, dentre os quais se destaca "Miss Dollar". A respeito da personagem que dá título ao conto, o narrador afirma que “A Miss Dollar do romance não é a menina romântica, nem a mulher robusta, nem a velha literata, nem a brasileira rica. Falha desta vez a proverbial perspicácia dos leitores; Miss Dollar é uma cadelinha galga." (AssIS 1994: 2). Nesse trecho é possível perceber um dos traços estilísticos machadianos: a articulação das palavras de modo a brincar com a imaginação do leitor.

No início do conto, o narrador apresenta supostas descrições de Miss Dollar, mas de modo surpreendente acaba por revelar a identidade da personagem, sendo esta pouco óbvia, mas cheia de significados. Segundo Seidel e Callipo (2010: 244), "O conto se passa na cidade do Rio de Janeiro no século XIX. A heroína é uma cadelinha galga, desse modo, há a desmistificação da heroína, com intuito de também desmistificar o Romantismo." Diante dessa breve análise sobre a personagem que leva o nome do conto, pode-se identificar possíveis intenções do autor, como a renovação da produção literária, a fim de inserir 
novas perspectivas sobre os indivíduos na sociedade, afastando-se, assim, de construções do Romantismo.

\subsection{A primeira tradução de Oliver Twist (1838) para o português brasileiro: folhetim e livro}

Como citado anteriormente, a primeira tradução de Oliver Twist (1838) para o português brasileiro começou a ser publicada no dia 23 de abril de 1870, por meio de folhetim no Jornal da Tarde; Machado de Assis traduziu 28 capítulos. Em 2011, a editora Hedra editou um volume com a tradução dos 28 capítulos de Machado completada pelo escritor Ricardo Lísias.

Vale destacar que, nos trechos analisados são os traduzidos por Machado de Assis, foram utilizadas as citações do livro a fim de facilitar a localização. Observando a tradução, realizada por Machado de Assis, segundo as normas tradutórias elaboradas por Toury (2012) pode-se considerar que na norma inicial prevalece o princípio de aceitação, pois o texto-alvo se aproxima da culturaalvo, como é exemplificado no excerto a seguir:

- Carlota - disse a Sra. Sowerberry, que acompanhara Oliver -, dê a esse pequeno os restos que se puseram de lado para dar ao cão; ele não voltou hoje à casa, passará sem comer. E espero que não torças o nariz, meu pecurrucho. Oliver, cujos olhos faiscavam com a ideia de comer carne e morria de vontade de a devorar, respondeu que não, e os restos do jantar foram postos diante dele. (DICKENS 2013: 58)².

Nesse trecho, o tradutor insere a expressão 'não torças o nariz' para traduzir “[...] isn't too dainty to eat 'em [...]", assim como também usa o termo 'pecurrucho' para traduzir o substantivo boy. Ambas as escolhas do tradutor são termos usualmente utilizados no português brasileiro em 1870 .

2 Here, Charlotte,' said Mr. Sowerberry, who had followed Oliver down, 'give this boy some of the cold bits that were put by for Trip. He hasn't come home since the morning, so he may go without 'em. I dare say the boy isn't too dainty to eat 'em - are you, boy?' Oliver, whose eyes had glistened at the mention of meat, and who was trembling with eagerness to devour it, replied in the negative; and a plateful of coarse broken victuals was set before him. (DICKENS 1994: 35).

TradTerm, São Paulo, v.35, junho/2020, p. 164-185

www.revistas.usp.br/tradterm 
Vale destacar que, segundo Toury (2012), nenhuma tradução é definida como totalmente aceitável ou adequada; frequentemente um princípio destacase sobre outro, e possivelmente ambos constituem uma mesma tradução, como observa-se no trecho a seguir: "Chegando ao fim do atalho, achou-se Oliver na grande estrada. Eram oito horas; e, posto que estivesse já a cinco milhas da cidade, correu e escondeu-se por trás de uma cerca até meio-dia;" [...] (DICKENS 2013: 85). Nesse excerto, o tradutor manteve a unidade de medida usada pelo autor do texto, a qual está de acordo com a cultura de partida e afasta-se da cultura de chegada, pois no Brasil não é comum que a distância seja calculada em milhas, mas em quilômetros.

O segundo conjunto de normas, as preliminares, compreendem as escolhas dos agentes literários, como inicialmente a escolha do texto-fonte e a definição se a tradução será direta ou tradução indireta. Machado de Assis optou por desenvolver uma tradução indireta, e utilizou por texto-fonte a tradução francesa de A. Gerardin, publicada pela Librairie de L. Hachette et Cie em Paris em $1864^{3}$. Tal escolha é justificada por Massa (2008), que afirma que, quando Oliver Twist foi traduzido Machado de Assis possuía um domínio maior da língua francesa do que da língua inglesa.

Ao analisar os 28 primeiros capítulos das duas edições, o folhetim e o livro, verificou-se que houve poucas alterações, como a revisão ortográfica e a estrangeirização de nomes. A revisão ortográfica ocorre de modo a ajustar a grafia do português brasileiro do século XIX para a do século XXI, como se pode observar na citação do folhetim:

D'entre os varios monumentos publicos que ennobrecem uma cidade de Inglaterra, cujo nome tenho a prudencia de não dizer, o á qual não quero dar um nome imaginario, um existe comum á mór parte das cidades grandes ou pequenas: é o asylo da mendicidade. (DICKENS 1870: 1 ).

Na edição revisada, após 130 anos, e publicada em livro pela editora

${ }^{3}$ Informação apresentada por Ricardo Lísias na introdução de Oliver Twist, publicado pela Editora Hedra, em 2002.

TradTerm, São Paulo, v.35, junho/2020, p. 164-185

www.revistas.usp.br/tradterm 
Hedra o mesmo trecho é apresentado com modificações na acentuação de algumas palavras, como 'varios' por 'vários', 'publicos' por 'públicos', 'prudencia' por 'prudência', 'á' por 'à' e 'imaginario' por 'imaginário'. Também se identificaram 4 alterações de grafia, como é possível observar:

Dentre os vários monumentos públicos que enobrecem uma cidade de Inglaterra, cujo nome tenho a prudência de não dizer, e à qual não quero dar um nome imaginário, um existe comum à maior parte das cidades grandes ou pequenas: é o asilo da mendicidade. (DICKENS 2013: 29).

No excerto acima foram modificadas as grafias das palavras 'D'entre' para 'Dentre”, na qual retirou-se o apóstrofo; 'ennobrecem' para 'enobrecem', com a supressão da letra 'n'; na expressão 'á mor' substitui-se por 'à maior', nesse caso, também se alterou o acento agudo pela crase; 'asylo' por 'asilo', com a substituição da letra ' $y$ ' por ' $i$ '. Considerando o intervalo de tempo entre as publicações das duas edições, a revisão ortográfica e a sua atualização constituem uma parte fundamental para a aceitação do texto-alvo na cultura de chegada, pois facilita a compreensão do leitor.

A segunda alteração identificada consiste na estrangeirização de dois nomes, o do autor e o do personagem protagonista. No folhetim, Machado de Assis, ou o editor, domesticou o nome Charles Dickens, empregando Carlos Dickens. 0 nome do romance e do personagem protagonista foi aplicado na tradução machadiana como Oliveiro Twist ao invés de Oliver Twist. Vale destacar que o nome dos outros personagens, também domesticados pelo tradutor, não foram alterados no processo de reedição para o livro, permanecendo do modo como foi traduzido em 1870. Diante dos dados expostos, é possível considerar que essas alterações foram realizadas com o intuito de deixar explícito que o romance é estrangeiro, e destaca-se o nome do tradutor para enfatizar que foi traduzido por um autor renomado.

O romance dickensiano foi selecionado para fazer parte da coleção 'Tradutores', composta por obras traduzidas por autores renomados. No artigo publicado em 2 de abril de 2001 no Jornal do Commércio, sobre o lançamento da 
tradução concluída de Oliver Twist, Ubiratan Brasil cita o depoimento de um diretor da Editora Hedra, "Foi seu nome [do tradutor Machado de Assis] que despertou nossa atenção e que nos motivou a publicar em livro a sua versão do 'Oliver Twist'”. (BRASIL 2001: A28). Ainda nesse sentido, essa edição foi publicada em formato de livro de bolso, com um preço mais acessível. Uma explicação plausível para as alterações no texto, além da seleção da obra e a escolha do formato, do livro.

Como se pode observar nos escritos de LefEVERE (2007), o mecenato atua diretamente na produção do sistema literário. Analisando-se a tradução de Oliver Twist é possível inferir a influência do componente econômico por meio dos agentes do mecenato durante todo o processo tradutório, desde a seleção da obra até a escolha do formato do livro.

Como já mencionado, o romance dickensiano foi escolhido para compor uma coleção específica da editora Hedra. Assim, pode-se considerar que o formato do livro, de bolso, também foi determinado a fim de tornar mais acessíveis as traduções, atingindo um público maior e, consequentemente, ampliando as vendas.

Na edição publicada em 2002 de Oliver Twist, há uma introdução do tradutor Ricardo Lísias. Nesse paratexto, o tradutor descreve as particularidades do trabalho desenvolvido, explicando os desafios e as suas escolhas tradutórias. Lísias explica que:

Se esta breve introdução for concluída no prazo combinado, terão se passado dois anos a partir do momento em que recebi o convite para terminar o trabalho de Machado de Assis e, um pouco movido pelo espírito de aventura intelectual, ciente dos riscos que ele impunha, decidi aceitá-lo. 0 trabalho pareceu-me atraente pois, além do convívio íntimo com a obra de um estilista notável, permitir-me-ia largas doses de criatividade. (LísIAS 2002: 24).

No que se refere às escolhas machadianas, o tradutor ainda optou por preservar escolhas linguísticas adotadas na primeira tradução, como "pequerrucho" e "a mostarda ia subindo o nariz", a fim de manter o estilo 
consistente.

\section{A estilística machadiana em Oliver Twist e "Miss Dollar"}

Nesta etapa da pesquisa, o objetivo foi identificar e analisar traços da escrita machadiana, tanto na tradução de Oliver Twist quanto em "Miss Dollar". No artigo de Ubiratan Brasil, citado anteriormente, Ricardo Lísias apresenta algumas características da tradução machadiana:

Um grande número de próclises; Expressões pouco comuns, como "lho" e "to"; Uso demasiado de expressões no infinitivo e quase raro de gerúndios; Uma larga utilização de imperativos e de regências diversas ("pisar o cão" e não "no cão"); Pouca aglutinação de preposições com artigos ("em casa de" e não "na casa de"); Expressões que estão fora de uso, como "pecurrucho", "dou-the cabo do canastro" que significa "mato", e "rinchar os sapatos" (arrastar). (BRASIL 2001: A28).

Diante dos apontamentos realizados pelo tradutor e a fim de analisá-los, cabe apresentar e identificar o terceiro conjunto de normas de Toury (2012), as normas operacionais. Este é o conjunto de escolhas realizadas no desenvolvimento da tradução, categorizadas em normas matriciais e normas textuais. As primeiras incluem os acréscimos, omissões ou alterações realizadas na tradução, últimas se referem às escolhas linguísticas realizadas pelo tradutor ou pelo editor, as quais podem ser indícios do estilo do tradutor. Machado de Assis reduz vários trechos de Oliver Twist, no excerto a seguir:

- Bom! - disse o Sr. Bumble, parando e lançando um olhar feroz ao seu protegido. - De todas as crianças mais ingratas, mais viciosas que tenho visto, você é...

- Não, não senhor - disse Oliver soluçando e agarrando-se à mão que empunhava a famosa bengala. - Não, não senhor; eu quero ser bom; sim eu hei de ter juízo... eu sou criança... eu sou... 
tão... tão... (DICKENS 2013: 56-57).

"Well!' exclaimed Mr. Bumble, stopping short, and darting at his little charge a look of intense malignity. 'Well! Of all the ungratefullest, and worst-disposed boys as ever I see, Oliver, you are the

- "No, no, sir, 'sobbed Oliver, clinging to the hand which held the well-known cane; 'no, no, sir; I will be good indeed; indeed, indeed I will, sir! I am a very little boy, sir; and it is so - so - ' (DICKENS 1994: 33).

Machado de Assis retira 'short' em 'stopping short', 'Well!' da segunda frase, 'boys' em 'worst-disposed boys' e o nome 'Oliver'. Na tradução para o português brasileiro, o olhar do Sr. Bumble para Oliver é descrito como 'feroz' enquanto, no texto-fonte, o autor descreve o olhar como um 'olhar de intensa malignidade', escolhas linguísticas que salientam a maldade representada pelo personagem. Mais adiante, a supressão do termo 'indeed' retira um pouco da carga emocional do personagem Oliver, que durante a narrativa representa o bem.

Segundo Massa (2008), as supressões realizadas justificam-se pelo desejo do tradutor de naturalizar a obra e, também, atenuar as características soturnas da Era Vitoriana. Em um estudo acerca dessas alterações causadas ao texto dickensiano, Camêlo (2013) apresenta suas considerações, observando que:

[...] dadas as omissões/alterações de grande parte dos segmentos em que o narrador opina e ironiza as personagens e situações, aquele veio crítico do romance dickensiano não parece se projetar na tradução de Machado. E considerando que é principalmente via narrador que as personagens nos são dadas a conhecer, frequentemente de forma problematizada via comentários ácidos do narrador, constatamos também que as personagens perdem em complexidade. (111-112).

Essas modificações no texto alteram a construção da personalidade dos personagens. Isso ocorreu no trecho, citado anteriormente, em o tradutor não traduz o termo 'indeed' na fala do personagem Oliver. Especificamente nesse exemplo, as palavras suprimidas influenciam na carga emocional do personagem. Consequentemente, amenizam a crítica da sociedade britânica.

TradTerm, São Paulo, v.35, junho/2020, p. 164-185 www.revistas.usp.br/tradterm 
A temática da obra é apresentada para o público brasileiro de modo mais brando, sem atenuar os problemas sociais de um polissistema cultural diferente daquele no qual o leitor está inserido. Ao longo de toda a tradução, Machado de Assis exclui o sentimentalismo exacerbado e a violência. Para Massa (2008), essas alterações foram realizadas porque o tradutor buscou adaptar a leitura ao gosto do público, apresentando traços do seu estilo próprio como escritor.

As escolhas linguísticas usadas na tradução de 1870 e que são mantidas na edição da editora Hedra não são empregadas frequentemente. Um exemplo se encontra no excerto; "Durante alguns instantes, o Sr. Bumble contemplou pasmado a cara assustada e triste de Oliver; tossiu três ou quatro vezes, como um homem endefluxado, e disse a Oliver que enxugasse os olhos e tivesse juízo." (DICKENS 2013: 57), é empregado o adjetivo ‘endefluxado’ para se referir ao estilo de tossir do Sr. Bumble.

Para o leitor não coetâneo da tradução do folhetim, essas expressões que causam estranhamento são exemplos do que, segundo a teoria de elementos da tradução, elaborada por Venuti (2002), constituem-se os resíduos mantidos na tradução reeditada. Considera-se que, às vezes, a compreensão desses resíduos ocorre por meio da contextualização presente no texto, enquanto, outras vezes se faz necessário consultar o significado de determinadas palavras.

Como apresentado anteriormente, a tradução machadiana de Oliver Twist parece aproximar-se mais da cultura de chegada, a brasileira, do que da cultura de partida, a inglesa, pois o tradutor insere expressões do português brasileiro quando possível, como no trecho citado anteriormente "Não torças o nariz". Esse dado conduz este estudo à verificação das semelhanças presentes nas escolhas linguísticas do tradutor aplicadas ao romance britânico, contrapondo as evidências com um conto produzido pelo tradutor, publicado no mesmo ano em que a tradução foi realizada. Assim como indicado por Ricardo Lísias, no romance, Machado de Assis emprega com frequência a próclise "lhes":

- A senhora dá caldo aos meninos? - perguntou o Sr. Bumble acompanhando com o olhar a operação da mistura.

- Decerto que lhes dou caldo - disse ela -, posto que custa 
caro; mas eu não posso ver sofrer; custa-me muito vê-los doentes. (DICKENS 2013: 37).

Essa escolha machadiana é constantemente aplicada no conto "Miss Dollar", como se pode observar: "Não the contarei as insônias e as lágrimas, as esperanças e os desencantos, páginas tristes deste livro que o destino põe nas mãos do homem para que duas almas o leiam." (Assıs 1994: 13). Além do pronome oblíquo 'lhe', há na escrita machadiana o uso constante de outros pronomes oblíquos, que podem causar estranhamento ao leitor não contemporâneo, pois não são comumente utilizados no português brasileiro atualmente, dentre os quais se destacam 'mo', 'lho', 'lha'.

Essas marcas estão presentes nas duas obras analisadas nesta pesquisa: o 'mo' é empregado em dois trechos do conto, "Não mo acusem de chofre; Mendonça era homem inteligente, instruído e dotado de bom senso; [...]". (Assis 1994: 6), e “[...] perdoe-me se ousei escrever-lhe quando seus olhos expressamente mo proibiram." (AssIs 1994: 13). A utilização do pronome com termos desconhecidos ocorre com frequência nos textos de Machado de Assis, como se pode observar na tradução do romance britânico:

A Sra. Mann levantou as mãos em sinal de espanto; depois disse:

- Mas como é que ele tem um nome de família?

O bedel empertigou-se com certo orgulho.

- Fui eu que lho inventei - disse ele.

- O senhor? (DICKENS 2013: 38).

No trecho citado, o tradutor usa o verbo 'empertigar' para descrever a reação do bedel diante da fala da Sra. Mann. Essa escolha é acompanhada do pronome 'lho' em próclise. Ambas as formas aplicadas no texto em 1870 foram mantidas na publicação da editora Hedra. Esse artifício literário também é apresentado no conto:

O sentido da carta era ainda mais lacônico do que a expressão. Mendonça leu-a muitas vezes, a ver se a completava; mas foi trabalho perdido. Uma cousa concluiu ele logo; era que havia cousa oculta que arredava Margarida do casamento; depois 
concluiu outra, era que Margarida ainda the perdoaria segunda carta se lha escrevesse. (Assis 1994: 14).

O autor utiliza o adjetivo 'lacônico' para descrever que o sentido da carta, enviada pela personagem Margarida para o personagem Dr. Mendonça, era conciso. Mais adiante, nesse mesmo trecho, Machado de Assis emprega o pronome oblíquo 'lha', ao referir-se à hipótese de enviar outra carta para Margarida. Em um trecho anterior ao citado, encontra-se outro artifício do autor, o uso dos verbos no infinitivo, como pode ser visto no trecho a seguir, "Quando Mendonça disse a Andrade haver escrito a Margarida, o amigo do médico entrou a rir despregadamente". (AssIs 1994: 13). Neste episódio, o autor utilizou os verbos 'haver' e 'rir' no infinitivo, além de empregar o advérbio 'despregadamente'. Algumas das escolhas empregadas pelo autor e tradutor que foram destacadas até o momento não podem ser definidas como uma característica de Machado de Assis, pois não foram encontrados indícios que confirmem tal hipótese, podendo ser essas apenas diferenças de registro, já que o português brasileiro sofreu transformações ao longo do tempo.

A tese intitulada A composição do estilo do contista Machado de Assis, desenvolvida por Deise J. T. de Freitas (2007), é um estudo acerca do estilo da escrita Machadiana, que busca verificar o processo de amadurecimento e transformação da escrita para identificar traços que caracterizam o estilo machadiano, tendo por objeto principal de estudo os contos escritos pelo autor. Após a análise do vocabulário presente nos contos, a pesquisadora afirma que "Se a originalidade não está no vocabulário, vamos procurá-la em outro aspecto. [...] investigamos a construção das frases e a distribuição do texto, a partir da análise da pontuação." (FreITAS 2007: 117).

Após a análise da extensão das frases e do uso da pontuação, FrEITAS (2007: 126) constatou que os primeiros contos escritos são mais extensos e possuem um número maior de diálogos, o que necessita de um maior uso de sinais de pontuação. Observando os dados analisados do conto "Miss Dollar" constatou-se que: 
Dos sete contos que o compõem [Contos Fluminenses], apenas um é de fato deficitário MiDo (Miss Dollar), que é o mais narrativo do volume, fugindo aos excessivos diálogos de contos como o SAug ( $O$ segredo de Augusta), estando abaixo da média que compreende a margem de erro. (FREITAS 2007: 128)

Diante dos dados apresentados é possível considerar que conforme o passar do tempo Machado de Assis reduziu o número de diálogos e o uso de sinais de pontuação, exceto no conto "Miss Dollar”, publicado em seu primeiro livro de contos em 1870, no qual já deixa impressas essas marcas estilísticas. Segundo FREITAS (2007), a frase mais longa e o texto mais narrativo vão se fixando como opção de Machado e sua repetição ao longo da linha do tempo vai consolidando essa forma como um padrão estilístico, uma marca do autor. (133). Outra marca estilística da escrita machadiana é a utilização da ironia para a construção de suas obras, como é possível verificar por meio de um trecho de Miss Dollar:

Mais esperto que os outros, acode um leitor dizendo que a heroína do romance não é nem foi inglesa, mas brasileira dos quatro costados, e que o nome de Miss Dollar quer dizer simplesmente que a rapariga é rica. A descoberta seria excelente, se fosse exata; infelizmente nem esta nem as outras são exatas. A Miss Dollar do romance não é a menina romântica, nem a mulher robusta, nem a velha literata, nem a brasileira rica. Falha desta vez a proverbial perspicácia dos leitores; Miss Dollar é uma cadelinha galga. (ASSIS 1994: 2-3).

Como já citado anteriormente, Machado de Assis brinca com o seu leitor no início do conto, lança suposições a respeito da personagem principal, com uma de suas principais características, a ironia. Segundo Perrot (2008: 152), “[...] a característica mais marcante da ironia está justamente nas intervenções do autor-narrador direcionadas ao seu leitor-narratário, suspendendo em diversos momentos a aura ficcional do texto.". Assim como no trecho citado, ao longo do conto o autor interfere no curso narrativo, e o narrador passa a dialogar diretamente com o leitor.

Semelhante a Machado de Assis, Dickens também possui como parte de seu estilo literário o uso da ironia. 0 autor britânico utiliza esse recurso estilístico 
para a construção de sua crítica em relação à sociedade britânica da época, direcionando-a para as instituições sociais que têm por função auxiliar a população menos favorecida, assim como também critica a classe alta da sociedade.

No processo de tradução, Machado de Assis realiza modificações no texto de Oliver Twist, como a supressão de trechos, como palavras, frases mais curtas ou mais extensas, ação que por vezes pode ser interpretada como uma suavização do texto e assim o artifício dickensiano de criticar por meio de ironia pode ser apagado do texto traduzido. Observando o texto em português e em inglês, observa-se que Machado faz supressões:

Durante os oito ou dez meses que se seguiram, Oliver Twist foi vítima de um sistema contínuo de trapaças e decepções.

Foi criado com mamadeira.

As autoridades da paróquia perguntaram com dignidade às autoridades do asilo se não havia alguma mulher, residente no estabelecimento, que pudesse dar a Oliver Twist a consolação e o alimento de que ele carecia. (DICKENS 2013: 33)

For the next eight or ten months, Oliver was the victim of a systematic course of treachery and deception. He was brought up by hand. The hungry and destitute situation of the infant orphan was duly reported by the workhouse authorities to the parish authorities. The parish authorities inquired with dignity of the workhouse authorities, whether there was no female then domiciled in 'the house' who was in a situation to impart to Oliver Twist, the consolation and nourishment of which he stood in need. (DICKENS 1994: 4)

O tradutor suprime a frase "The hungry and destitute situation of the infant orphan was duly reported by the workhouse authorities to the parish authorities".

Prosseguindo com a análise, a segunda mudança a ser destacada refere-se à possível suavização da crítica de Dickens:

As autoridades do asilo responderam humildemente que não havia; à vista do quê, as autoridades da paróquia tiveram a 
humanidade e a magnanimidade de ordenar que Oliver fosse mandado para uma casa dependente do asilo, situada a três milhas de distância, onde uns vinte ou trinta infratores da lei dos pobres passavam o dia a rolar pelo chão sem medo de comer muito nem andar agasalhados demais. (DICKENS 2013: 33)

The workhouse authorities replied with humility, that there was not. Upon this, the parish authorities magnanimously and humanely resolved, that Oliver should be 'farmed,' or, in other words, that he should be dispatched to a branch-workhouse some three miles off, where twenty or thirty other juvenile offenders against the poor-laws, rolled about the floor all day, without the inconvenience of too much food or too much clothing, under the parental superintendence of an elderly female, who received the culprits at and for the consideration of sevenpence-halfpenny per small head per week. (DICKENS 1994: 4-5)

No trecho que Machado de Assis traduz “[...] onde uns vinte ou trinta infratores da lei dos pobres passavam o dia a rolar pelo chão sem medo de comer muito nem andar agasalhados demais [...]”, Dickens havia escrito “[...] where twenty or thirty other juvenile offenders against the poor-laws, rolled about the floor all day, without the inconvenience of too much food or too much clothing, [...]", é possível observar que o tradutor não traduz as palavras "without the inconvenience". A omissão de "sem a inconveniência"4 pode retirar a intencionalidade do texto em criticar a situação na qual as crianças órfãs eram criadas, pois a alimentação e as roupas são elementos básicos de sobrevivência, mas a sociedade britânica considerava dá-los aos mais pobres, principalmente aos desprovidos de família, como uma inconveniência.

Em relação à supressão da ironia e a sua criação em determinados trechos, pode-se considerar que ambas as ações são parte da intencionalidade e composição do projeto literário do tradutor. Para Duarte (2009):

0 projeto literário machadiano, exposto no "Instinto de nacionalidade" (1873) e materializado em tantos escritos, comporta a argúcia com que trata, na condição de sujeito periférico, o poder e o risco inerentes à palavra impressa, numa sociedade patriarcal e escravista como a do Brasil do século XIX. O escritor cumpre a condição de "homem do seu tempo e do seu país", mesmo quando parece tratar de assuntos os mais

4 Tradução nossa.

TradTerm, São Paulo, v.35, junho/2020, p. 164-185 www.revistas.usp.br/tradterm 
longínquos. Nesse tenso jogo entre o dado local ou nacional e as muitas referências universalizantes, revela-se a ginga verbal do capoeirista, sempre pronto ao disfarce e ao engodo. (29).

Observando a delicadeza do assunto abordado por Dickens em sua obra, torna-se plausível a hipótese de que o tradutor tenha usado um "disfarce" proposital na tradução da crítica presente no texto-fonte. Conforme Duarte (2009), a "capoeira verbal” de Machado de Assis ocorre "[...] em função do público alvo e da própria estrutura dos periódicos mencionados, tinha o autor que conviver todo o tempo com cerceamentos mais ou menos explícitos de sua expressão, o que leva automaticamente à busca de disfarces." (31-32). Diante disso, observa-se a genialidade de Machado de Assis enquanto escritor e tradutor.

\section{Considerações finais}

Nesta pesquisa foi proposto um estudo da tradução machadiana para o português brasileiro de obra Oliver Twist (1838), de Charles Dickens, assim uma análise de corpus paralelo, tendo por objetos o romance dickensiano e o conto "Miss Dollar", de Machado de Assis, observando os traços da estilística machadiana em ambas as obras.

$\mathrm{Na}$ primeira parte da pesquisa foi realizada a identificação das características dos autores, das obras e dos polissistemas de partida e de chegada. Quanto às particularidades dessa tradução, vale destacar que é muito peculiar e possui diversos aspectos a serem problematizados. Entretanto, este estudo restringe-se a verificar apenas algumas propriedades da obra.

Buscou-se verificar as alterações entre as duas edições da tradução de Oliver Twist, publicadas em folhetim e livro. Observou-se que o texto publicado no folhetim sofreu duas modificações ao ser reeditado para o livro. A primeira consiste na revisão ortográfica, apenas atualizando a grafia de algumas palavras. A segunda modificação refere-se à estrangeirização do nome do autor e do 
personagem protagonista.

Como última etapa foi desenvolvida a análise do corpus paralelo, apontando traços da escrita machadiana em Oliver Twist e "Miss Dollar".

De modo geral, em ambas as obras se encontram traços marcantes da escrita machadiana, como a exploração da ironia, presente no conto "Miss Dollar" e que é inserida em alguns trechos da tradução de Oliver Twist. Entretanto, verificou-se que na tradução de Machado de Assis há a omissão de trechos em que Charles Dickens constrói, por meio da ironia, críticas à sociedade britânica.

$\mathrm{Na}$ tradução, Machado de Assis exclui o sentimentalismo exacerbado e atenua os episódios de violência. Contudo, essa ação pode ter sido uma estratégia de Machado para aproximar o texto-fonte ao contexto de chegada, disfarçando temas e críticas, que possivelmente não seriam aceitos pelo sistema literário brasileiro de 1870. Além disso, o tradutor buscou adaptar a leitura ao gosto do público, conforme apresenta elementos do seu estilo de escritor. 


\section{Referências}

AssIS, M. d. "Miss Dollar". Contos Fluminenses. Rio de Janeiro: Nova Aguilar 1994. v. II. Disponível em: <http://www.dominiopublico.gov.br/download/ texto/bv000170.pdf>. Acesso em: 10 nov. 2017.

BRASIL, U. Terminada a tradução de "Oliver Twist" iniciada por Machado de Assis. Jornal do commercio. Rio de Janeiro, 1 e 2 abr. 2001. Livro, p. A28. Disponível em: <memoria.bn.br/DocReader/DocReader.aspx?bib=364568_ 19\&pesq=OLIVERTWIST>. Acesso em: 1 maio 2017.

BURGESS, A. A literatura inglesa. Tradução de Duda Machado. 2. ed. São Paulo: Ática, 2008.

CANDIDO, A. O romantismo no Brasil. São Paulo: Humanitas/FFLCH/SP, 2002.

CAMÊLo, F. Machado de Assis e a (re)escrita de Oliver Twist. Dissertação (Mestrado). 2013. 158 f. Programa de Pós-Graduação em Letras, Centro de Artes e Letras, Universidade Federal de Santa Maria. 2013. Disponível em: <http://www. periodicos.letras.ufmg.br/ index.php/o_eixo_ea_roda/ article/vie w/3284/3218>. Acesso em: 16 abr. 2017.

DuARTE, Eduardo de Assis. A capoeira literária de Machado de Assis. Machado de Assis em linha. São Paulo, Ano 2, n. 3, jun. 2009. Disponível em: <http: //machadodeassis.net/download/numero03/num03artigo03.pdf>. Acesso em: abr. 2019.

Dickens, C. Oliver Twist. Middlesex (England): Penguin Popular Classics, 1994.

DiCKENs. C. Oliver Twist. Tradução de Joaquim Maria Machado de Assis e Ricardo Lísias. São Paulo: Hedra, 2013.

DICKENS. C. Oliveiro Twist. In: Jornal da Tarde, Folhetim do Jornal da Tarde. Rio de Janeiro, 22 nov. 1870, p. 1. Disponível em: <http://memoria.bn.br>. Acesso em: 19 jul. 2016.

Even-Zohar, Itamar. Polysystem Studies. Poetics today, Durham, v. 11, n. 1, 1990, p.10-27. Disponível em:

<http://www.tau.ac.il/ itamarez/works/books/ez-ss1990.pdf>. Acesso em: 26 mai. 2016.

Freitas, Deise J. T. de. A composição do estilo do contista Machado de Assis. Tese (doutorado), 2007. 211 f. Universidade Federal de Santa Catarina, 
Programa de Pós-Graduação em Literatura, 2007. Disponível em: <https://repositorio.ufsc.br/xmlui/handle/123456789/90720>. Acesso em: 17 mar. 2019.

LefEVERE, A. Tradução, reescrita e manipulação da fama literária. Tradução de Claudia Matos Seligmann. Bauru: Edusc, 2007.

LísIAS, R. Introdução. In: DICKENS, C. Oliver Twist. Tradução de Joaquim Maria Machado de Assis e Ricardo Lísias. São Paulo: Hedra, 2013, p. 11-26.

MASSA, J. - M. Machado de Assis tradutor. Tradução de Oséias Silas Ferraz. Belo Horizonte: Crisálida, 2008.

Perrot, A. C. Machado de Assis: ironia e filiação literária. Revista da Anpoll, Florianópolis, v. 1, n. 24, 2008, p. 139-156. Disponível em: $<$ https://revistadaanpoll. emnuvens.com.br/revista/article/viewfile/21/10>. Acesso em: 17 mar. 2019.

Seidel, V. P. Callipo, D. M. A intertextualidade em "Miss Dollar" de Machado de Assis. Miscelânia. Revista de Pós-Graduação em Letras. Assis. v. 7, jan./jun. 2010. Disponível em: <https:// repositorio.unesp.br/handle/11449/126746>. Acesso em: 10 jan. 2018.

VenUtI, L. Escândalos da Tradução: por uma ética da diferença. Tradução de Laureano Pelegrin, Marcelino Villela, Marileide Dias Esqueda e Valéria Biondo. Bauru: Edusc, 2002.

Recebido em: 04/05/2019

Aceito em: 27/05/2020

Publicado em junho de 2020 